\title{
Aliviar siempre
}

\section{To relieve always}

\author{
Eugenio Matijasevic • Bogotá, D.C.
}

En opinión de Solón, el legislador por antonomasia y uno de los Siete Sabios de la Grecia clásica, nadie debería considerarse feliz antes del día de la muerte.

Cuenta Herodoto que cuando Solón visitó en Sardes a Creso, Rey de Lidia famoso por sus riquezas, éste le preguntó si a lo largo de su vida había conocido a alguien completamente feliz. El propio Herodoto al relatar la anécdota nos da la clave sobre el origen de la pregunta: Creso le había mostrado a Solón durante varios días sus innumerables bienes y adicto, como todos los poderosos, a las lisonjas, quería recibir de tan ilustre huésped una nueva alabanza. Solón, sin embargo, ajeno en extremo a la adulación, le respondió que sí, que él había tenido la oportunidad de conocer a alguien feliz: Tello, el ateniense.

Herido en su orgullo, pero incapaz de declarar abiertamente que estaba solicitando un elogio, Creso le preguntó a Solón cuáles eran los motivos para considerar a Tello un hombre feliz y Solón le respondió sin rodeos que, floreciendo su patria, Tello había visto crecer y prosperar en ella también a sus hijos y luego a sus nietos, antes de encontrar una muerte heroica en la batalla de Eleusina, defendiendo de manera victoriosa ese florecimiento y esa prosperidad. Creso no tuvo otra posibilidad que estar de acuerdo pero, persiguiendo lo que ansiaba, arremetió de nuevo y le pidió a Solón que le contase a quién más, fuera de Tello, consideraba feliz. Solón volvió a frustrarlo mencionando esta vez a Cleobis y Biton, dos argivos que, jóvenes aún, alcanzaron, como Tello, una muerte gloriosa, aunque no en defensa de su libertad y la de los suyos sino, literalmente, llamados por los dioses en el transcurso de unos ritos religiosos y luego de haber dado claras pruebas de amor filial.

En este punto Creso ya no aguantó más y le reclamó a Solón el que, a él que poseía tantas riquezas, no lo considerara entre los felices y no lo juzgara digno de figurar siquiera al lado de esos "hombres vulgares" que había traído a ejemplo. Solón no se inmutó con la ira de su anfitrión, antes bien, le recordó que la fortuna es cambiante y que si, en algún momento, somos mimados por la suerte, en el instante siguiente todo puede haber sido trastocado: "La vida del hombre ;oh Creso! -le dijo- es una serie de calamidades. En el día sois un monarca poderoso y rico, a quien obedecen muchos pueblos; pero no me atrevo a darte aún ese nombre que ambicionáis, hasta que no sepa cómo habéis terminado el curso de vuestra vida" (1).

Para Solón no era posible que un mortal reuniese todos los bienes requeridos para ser feliz (entre los que mencionaba: disfrutar de buena salud, no tener dificultades, criar hijos honrados y ser de buena presencia) porque, de la misma manera que ningún país produce todo cuanto necesita "abundando de unas cosas y careciendo de otras", no existe un hombre capaz de producir todo lo bueno; y aún así, si lo hubiese reunido, no podría llamarse feliz "si después no lograse una muerte plácida y agradable".

Cuenta Herodoto que Creso se despidió de Solón considerándolo un ignorante que cifraba la felicidad no en los bienes actuales de un hombre, sino en el balance final de su vida.

Una frase de Solón resume, en el relato de Herodoto, la concepción que aquel tenía de la felicidad más como un proceso en desarrollo a lo largo del ciclo vital humano que como un estado de ánimo fugaz presente en algún momento de ese mismo ciclo: "antes que alguien

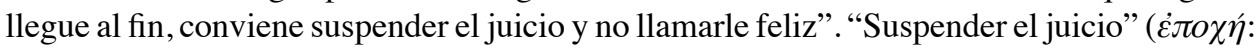
epojé), fue una fórmula muy utilizada por los griegos para significar que no era posible tomar una decisión racional a favor o en contra de un determinado asunto con base en la información disponible (más tarde los escépticos pirrónicos transformarían esta máxima en la base de toda su filosofía) (2). En el caso de la frase de Solón "suspender el juicio" viene
Dr. Eugenio Matijasevic: Editor General Acta Médica Colombiana. Bogotá, D.C E-mail: eugenio.matijasevic@gmail.com Recibido: 04/IV/2011 Aceptado: 05/IV/2011 
a significar: "no puedo ni afirmar ni negar de alguien que haya sido feliz sino en el momento de su muerte".

Los términos utilizados por Herodoto cada vez que en su relato Solón se refiere a la felicidad o a un hombre feliz

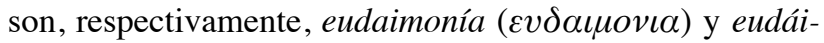
mon ( $\varepsilon v \delta \alpha \iota \mu o v)$. En griego clásico los conceptos de placer ( $\dot{\delta} \delta o v \eta ́$ : hedoné), alegría ( $X \alpha \varrho \alpha ́$ : chará), compasión ( $\varepsilon \lambda \varepsilon o \varsigma:$ eleos), terror ( $\Phi$ ó $\beta o \varsigma$ : fobos) y otros muchos para otras tantas emociones ( $\pi \alpha \theta o \varsigma$ : pathos), se utilizaban con sentidos bastante similares a los que les damos en la actualidad, pero no existe una correspondencia exacta de sentido, aunque sí hay afinidades innegables, entre los términos eudaimonía y felicidad. Uno de los aspectos más importantes en los que difieren es que el segundo es un término para designar una emoción, un estado mental, mientras que el primero designa una manera de estar y obrar en el mundo. Sin embargo, aunque el concepto de eudaimonía parezca un poco difícil de equiparar al de felicidad existe, desde el punto de vista semántico y etimológico, un sendero que los une.

Eudaimonía significa literalmente un buen dáimon $(\delta \alpha \iota \mu \nu v)$. Los dáimones eran dioses menores, una especie de demonios personales (en la actualidad diríamos ángeles de la guarda, ya que con el advenimiento del cristianismo el término dáimon y sus derivados pasaron a tener connotaciones negativas) ligados, uno a uno, a la vida de cada individuo desde su nacimiento. Para los griegos contemporáneos de Herodoto el dáimon individual determinaba, total o parcialmente, el devenir de cada persona, a tal grado que en ocasiones, sobre todo en la obra del propio Herodoto, parece

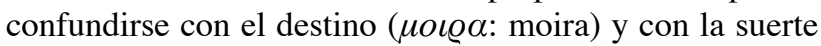
( $\tau v \chi \eta$ : tyqué). Sin embargo, el dáimon no era, de ninguna manera, un alter ego, ni se consideraba como una fuerza externa a la persona, sino como una parte fundamental del propio ser, al igual que el aspecto físico o el carácter (3). El dáimon venía con cada persona al mundo y era, para poetas como Teognis, historiadores como Herodoto y, en general, para los griegos de su tiempo, inmodificable. Eric Dodds advierte en Los Griegos y lo Irracional que Heráclito se opuso a esta superstición con denuedo, enseñando, sin el menor éxito, que "el carácter de un hombre es su destino".

Para Herodoto y sus contemporáneos, los seres humanos llegamos a ser lo que somos debido a los designios de nuestro dáimon, incluso aunque en apariencia percibamos que nuestra voluntad, nuestro carácter o nuestras características físicas tienen algún influjo sobre nuestros logros. Por ello, aquel que alcance en la vida las mayores bondades que un hombre pueda desear, es indudable que tiene un buen dáimon $\mathrm{y}$, por tanto, recibirá el calificativo de eudáimon. Seguramente, en los términos de Solón, alguien así alcanzará la eudaimonía si logra, además, una muerte gloriosa o si, al menos, antes de la muerte su condición de eudáimon no se ve trastornada por los avatares de la fortuna.

Para la época de Sócrates ya nadie creía en el dáimon, a no ser para referirse a algo así como la voz de la conciencia ("Está conmigo desde niño -dice Sócrates en la Apología refiriéndose a su dáimon- tiene forma de voz y, cuando se manifiesta, siempre me disuade de lo que voy a hacer, jamás me incita") (4). Sin embargo, el nombre de eudaimonía había quedado para referirse, no a la felicidad como la concebimos actualmente, sino a una vida vivida de tal manera que respondía en la práctica a la pregunta socrática fundamental: ¿Cómo debemos vivir nuestras vidas? ("Después de todo -le había dicho Sócrates a Trasímaco en el primer libro de La República- nuestra discusión no es acerca de algo de importancia menor, sino acerca de cómo debemos vivir nuestras vidas") (5).

Sin lugar a dudas, Sócrates, el más sabio de los hombres según el oráculo de Delfos (6), sabía la respuesta: en el Critón, a punto ya de beber la cicuta, sus amigos le ofrecen ayuda para que escape de la prisión y se salve de morir, pero la respuesta de Sócrates, absolutamente coherente con lo que ha sido hasta el momento su vida, es al mismo tiempo mortal para él: "No es vivir, sino vivir una vida buena lo que debemos considerar más importante"(7). Pero ¿qué es una vida buena?

En su Ética a Nicómaco, Aristóteles comienza por decir que todo el mundo está de acuerdo en que el mayor bien en la vida de un ser humano ("puesto que todo conocimiento y toda elección tienden a algún bien") es la felicidad ( $e u$ daimonía), aunque nadie se ponga de acuerdo sobre qué es exactamente ser feliz: "acerca de qué es la felicidad, dudan y no lo explican del mismo modo el vulgo y los sabios [...] a menudo, incluso, una misma persona opina cosas distintas: si está enfermo, la salud; si es pobre, la riqueza". Sin embargo, a pesar de las diferencias, existe para Aristóteles un aspecto común a todas las situaciones calificadas de felices (eudáimon): todos los seres humanos, hombres del común a la par que los sabios, "admiten que vivir bien y obrar bien es lo mismo que ser feliz (eudáimon)" (8).

Aristóteles se da entonces a la tarea de indagar qué se quiere decir exactamente cuando se habla de ser feliz (eudáimon) como sinónimo de una vida buena. Ya en su Ética Eudemia (considerada por muchos no sólo una obra previa a la Ética Nicomaquea sino también un esbozo de ésta) (9) también se había preguntado Aristóteles por la definición de felicidad e, incapaz de establecerla a partir de la opinión del común de la gente, había decidido preguntarle a los sabios (10). Punto por punto, a partir de las respuestas que sobre la felicidad otros sabios han dado en sus escritos o con su ejemplo, va descartando como fuente indudable de la $\mathrm{eu}$ daimonía el placer, los honores, las riquezas, los puestos de mando, la gloria, etc. para llegar a la propia conclusión de que lo único que nos hace verdaderamente felices es la virtud ( $\alpha \varrho \varepsilon \tau \eta \dot{\eta}$ : areté). Todo lo demás son sólo medios para alcanzar la eudaimonía o, en el peor de los casos, meros simulacros efímeros de supuesta felicidad. Podríamos sintetizar la visión de Aristóteles sobre este punto diciendo en castellano llano que no es lo mismo la vida buena que una buena vida.

Tampoco areté, aunque la traduzcamos casi siempre como virtud, tiene un equivalente preciso en castellano, pues 
el término recibió más tarde el influjo del cristianismo y no ha llegado hasta nosotros con el mismo sentido que tenía para los griegos. Para los contemporáneos de Aristóteles la areté consistía en el cumplimiento pleno de una función ( $\varepsilon \varrho \gamma o v$ : ergón): la areté de un constructor naval sería un buen barco; la de un buen estratega, la victoria; la de un buen médico, la salud de sus pacientes. También para Aristóteles la areté es, siempre, el resultado ( $\tau \dot{\lambda} \lambda o \varsigma:$ telos) de un propósito; la finalidad, el objetivo, del desarrollo de una función.

Pero si lo que nos hace verdaderamente felices es la areté y toda areté consiste en una actividad dirigida al cumplimiento pleno de una función ¿Cuál es, entonces, -se pregunta Aristóteles- la función de un ser humano? (11) ¿Cuál es el objetivo de sus actividades como ser humano? ¿Qué es lo que nos hace más humanos?. En De Anima (Sobre el Alma), para explicar que el alma ( $\psi v \chi \eta$ : psyché) no es otra cosa que la función de un ser vivo, había afirmado Aristóteles que "si el ojo fuera un animal, su alma sería la vista" (12). Este breve ejemplo basta para comprender qué lejos estamos de entender el concepto griego de psyché cuando lo traducimos al castellano como alma. Para Aristóteles todos los seres vivos, vegetales y animales, estamos dotados de alma, de tal manera que psyché es un concepto más afín al concepto de vida (ßíos: bios) que al de espíritu ( $л v \varepsilon v \mu \alpha$ : pneuma) con el que pasó a nuestra cultura a partir de la influencia del Mitraísmo y de otros cultos mistéricos que acompañaron el nacimiento del Cristianismo (13). Para Aristóteles "la palabra vivir hace referencia a múltiples operaciones" (14) y el alma humana participa de todas ellas puesto que tiene, para él, tres aspectos: uno nutritivo similar al de los vegetales (asimilar nutrientes y crecer), otro sensitivo similar al de los animales (moverse y percibir el medio) y, finalmente, uno intelectivo, el logos ( $\lambda o \gamma o \varsigma$ : término que puede ser traducido indistintamente como palabra o como razón) que es el que nos hace humanos. La función fundamental del ser humano, lo que nos hace verdaderamente humanos, es el logos, por tanto nuestra areté como seres humanos es llevar el logos, la razón, a su más pleno desarrollo.

Así que, de acuerdo con Aristóteles, si a lo largo de nuestra vida ejercitamos la razón y obramos siempre de acuerdo con ésta (para Aristóteles las acciones humanas ya no son, como entre sus antepasados, simples movimientos de autómata decretados por el dáimon), tendremos necesariamente que hacer ejercicio de las virtudes (areté) esencialmente humanas derivadas del logos. Estas son dos, la sabiduría

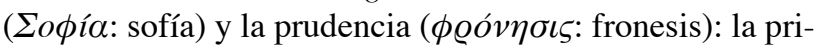
mera nos permite conocer cómo es el mundo, mientras que la segunda es una especie de sabiduría práctica que nos permite saber cómo actuar en el mundo, cómo inducir cambios en él mediante los medios correctos que nos permitan alcanzar la eudaimonía (15).

Aristóteles, al igual que Herodoto, acepta que la eudaimonía no es tarea de un día ("Pues la felicidad requiere, como dijimos, una virtud perfecta y una vida entera") (16), pero no está de acuerdo con el dictum de Solón transcrito por Herodoto, ya que, "si es menester ver el fin -dice Aristóteles- y juzgar entonces venturoso a cada uno no por lo que sea en ese momento, sino por lo que fue antes, ¿cómo no será absurdo que cuando uno es feliz (eudáimon) no se reconozca como verdad la felicidad (eudaimonía) [...] a causa de las mudanzas de las cosas?". Es decir: la felicidad es una actividad, un proceso ( sentimiento en la mente, una emoción ( $\pi \alpha ́ \theta o \zeta)$ generada por los giros incesantes de las vicisitudes de la fortuna, por tanto, el hombre verdaderamente eudáimon no puede ser un camaleón que cambia cada vez que circunstancias ajenas a él modifican su situación en el mundo: "en modo alguno se deben seguir las vicisitudes de la fortuna [para determinar quién es eudáimon y quien no]; porque, aunque la vida humana necesita de ellas, las que determinan la felicidad (eudaimonía) son las actividades de acuerdo con la virtud (areté)" (17). Para Aristóteles, el ejercicio permanente de la razón (logos) nos llevará a la excelencia (areté) y hará que como seres humanos alcancemos la eudaimonía y que seamos llamados eudáimon en todo momento, en cualquier circunstancia, incluso en la terrible circunstancia de la propia muerte.

Las enseñanzas de Aristóteles han sobrevivido más de veintitrés siglos a su creador. Primero en la escuela peripatética, luego entre los autores latinos (que utilizaban no el Latín sino el griego como lingua franca en los círculos intelectuales del vasto imperio) y, después, siempre en griego, entre los neoplatónicos (incluyendo neoplatónicos cristianizados como Agustín de Hipona). Con la caída del Imperio Romano de Occidente la tradición aristotélica se preservó en Bizancio, de donde pasó a Siria en donde sus obras fueron traducidas al siríaco y posteriormente al árabe, difundiéndose ampliamente entre los estudiosos árabes durante los largos años del medioevo. En Europa occidental los escritos de Aristóteles sólo se conocieron, inicialmente, en comentarios y traducciones fragmentarias al Latín, sobre todo de los libros de lógica, hechas por Boecio (480-524 EC), Casiodoro (490-585 EC) e Isidoro de Sevilla (570-636 EC) (18). Posteriormente, sobre todo en España, hubo comentarios y traducciones al latín, también fragmentarias, de las obras de Aristóteles, todas derivadas de las fuentes árabes y por tanto traducciones de las traducciones árabes del griego o del siríaco. La primera traducción de la Ética Nicomaquea al Latín se debe a un traductor anónimo del siglo XII y solo incluía los libros II y III. A partir del siglo XIII, con la cuarta cruzada y la caída transitoria de Bizancio en manos de los cruzados entre 1204 y 1261, fue posible para la Europa occidental reencontrar a Aristóteles en los textos originales griegos. La primera traducción completa de la Ética Nicomaquea al Latín se debe a Roberto Grosseteste y data de 1246, pero la más difundida fue una revisión de esta traducción hecha por Guillermo de Moerbeke hacia 1260 (19).

A estos primeros traductores de la Ética Nicomaquea del griego al latín no les fue fácil encontrar un término latino para traducir el término griego eudaimonía. Seguramente 
después de varias pruebas dieron con el término latino felicitas, que significa en general: suerte, buena fortuna y, obviamente, felicidad. Felicitas, a su vez, se deriva del adjetivo latino felix que se aplica a todo aquello que es fértil, fructífero, en especial a un terreno bien cultivado, pero también, por extensión, a una vida bien cultivada (20). Obviamente, felicitas no captura el sentido específico que un griego como Aristóteles podía darle a eudaimonía, pero, por forzada que parezca la equivalencia, hacer corresponder una vida guiada de acuerdo con un buen dáimon personal con una vida bien cultivada, habla muy bien del esfuerzo de los traductores por encontrar paralelismos lo más cercanos posibles, aunque en cada caso provinieran de metáforas muy diferentes sobre el desarrollo de la vida humana.

El término castellano felicidad se derivó sin dificultad del felicitas latino. Pero de la misma manera que felicitas no recogía de manera completa el sentido que eudaimonía tenía para los griegos, tampoco en este caso recogió felicidad el mismo sentido que le daban los romanos a felicitas (y mucho menos el que le daban los griegos a eudaimonía); de hecho, con el término felicidad se rompe el hilo conductor metafórico que unía a eudaimonía con felicitas. Según el Diccionario de la Real Academia Española (DRAE), en su vigésimosegunda edición, la palabra felicidad en castellano se refiere a un estado de ánimo, esto es, a un estado de la mente, a una emoción: "Felicidad 1.f. Estado del ánimo que se complace en la posesión de un bien" (21). La próxima edición del DRAE planea una enmienda en la definición de felicidad dándole al término una connotación no sólo emocional sino también corporal: "1. f. Estado de grata satisfacción espiritual y física" (22), pero aunque desaparece el énfasis exclusivo en lo emocional insiste de manera machacona en la idea de que se trata de un estado, de un momento en el decurso de la vida humana y no de un proceso tendiente hacia un fin, de una actividad con un propósito, como en los términos griego y latino.

Incluso aunque tratásemos de no dejarnos influir por las definiciones del DRAE, es indudable que, como cuando decimos "me siento feliz hoy", nuestra concepción actual de felicidad es puramente emocional, en agudo contraste con la concepción griega y latina de eudaimonía y felicitas que bien poco le deben a estados pasajeros del ánimo. Cuando Aristóteles llevó a cabo su indagación de filosofía práctica sobre la eudaimonía estaba lejos de interesarse por el sentido subjetivo de "sentirse alegre" o de "estar contento" (frases cuyos usos en la actualidad resultan indistinguibles de "ser felices") y, muy por el contrario, trataba de establecer cuáles eran las condiciones requeridas para que una persona fuera llamada eudáimon (hasta encontrarlas: que construyera activamente su vida desarrollando al máximo las facultades humanas derivadas de la razón, sin olvidar que para lograrlo también es necesario encausar los aspectos vegetativo y sensitivo de la psyché humana).

Dado que el término felicidad se funde y se confunde, al menos en nuestra cultura, con los conceptos de placer y alegría, son muchas las voces que se han unido en pro del propósito de no traducir nunca jamás ni eudaimonía ni felicitas comofelicidad, sino más bien como "florecimiento humano" o "posibilidad de fructificar" o "bienestar", términos que capturan mejor que felicidad los sentidos activo y objetivo de eudaimonía y de felicitas (23).

Advierto ya al final de estos comentarios sobre la eudaimonía, que he sido demasiado insistente en mostrar de qué manera Aristóteles la desliga de emociones como el placer y la alegría en un sentido positivo, o del dolor y la tristeza en un sentido negativo; a tal grado que podría llevar al lector a pensar que Aristóteles es un enemigo acérrimo de las pasiones o un tipo aburrido incapaz de buscar y encontrar alegría en las cosas sencillas de la vida cotidiana. Lejos de eso, Aristóteles fue un ser humano completo (y complejo), apasionado como el que más, con esposa, hijos, asuntos económicos qué atender, inmerso (con la altura que en todos sus actos lo caracterizó) en los conflictos políticos de su tiempo; el punto es que, y en ello hay que darle la razón, no es posible edificar una teoría política (sobre los deberes que como ciudadanos tenemos los unos con los otros para que cada uno pueda encontrar la mejor posibilidad de florecer en la ciudad) ni una teoría ética (sobre cómo debemos vivir la vida) que tengan posibilidades de funcionar en la práctica, a partir de elementos tan efímeros como las pasiones.

El propio Aristóteles tenía presente que al interior de su indagación filosófica existía una subdivisión insoslayable que se reflejaba claramente en sus obras escritas: de un lado las que el denominaba de carácter teórico ( $\theta \varepsilon \omega \varrho i ́ \alpha$ : theoría), en las que incluía todos sus escritos de lógica y sus tratados sobre física y metafísica al tiempo que sus estudios de ciencias naturales, y del otro las de carácter práctico $(\pi \varrho \hat{\alpha} \xi \iota \varsigma$ : praxis), entre las que incluía todos sus escritos sobre ética y política. Que él era consciente de dicha división lo deja en claro cuando refiriéndose en la Ética Nicomaquea al propio texto de la Ética Nicomaquea dice que "el presente tratado no es teórico como los otros, pues no investigamos para saber qué es la virtud, sino para ser buenos, ya que en otro caso sería totalmente inútil" (24). Para Aristóteles la filosofía práctica no es un mero ejercicio especulativo sino que tiene que producir un cambio real en nuestras vidas.

Sería de esperar que quien dedicó una buena parte de su obra (la que el propio Aristóteles denominó filosofía práctica) a indagar sobre cómo vivir una vida que valiese la pena vivirse, una vida buena, hubiera dedicado al menos unos párrafos a hablar de una muerte buena, pero el tema brilla por su ausencia en la obra de Aristóteles. El lector buscará en vano una mención siquiera de Aristóteles que se aproxime a la idea que esgrime Solón de una muerte buena: defendiendo la polis o llamado por los dioses. En general, cuando Aristóteles se refiere a la muerte lo hace en sus escritos de filosofía teórica y más precisamente en dos tratados que en la actualidad calificaríamos de tratados de ciencias naturales: el primero se llama De la Longevidad y de la Brevedad de la Vida y el segundo De la Juventud y de 
la Vejez, de la Vida y de la Muerte y de la Respiración (25). En ellos nos da su versión de cómo y por qué mueren los animales, nunca se refiere a cómo deberíamos morir. La única referencia a la muerte en la Ética Nicomaquea tiene lugar en el séptimo capítulo del libro III, dedicado a la valentía, en donde se opone al suicidio como salida a una situación difícil por considerarlo un acto de cobardía: "Pero el morir por huir de la pobreza o del amor o de algo doloroso, no es propio del valiente sino más bien del cobarde, porque es blandura rehuir lo que es penoso, y no sufre la muerte por ser noble, sino por rehuir del mal" (26).

Cabe obviamente la posibilidad de que en algún tratado Aristoteles se haya referido al problema de la muerte buena desde una perspectiva no teórica sino práctica, pero que ese tratado o el fragmento concerniente no hayan sobrevivido al paso del tiempo. Si nos basamos en las referencias que autores contemporáneos de Aristóteles hicieron a sus obras o en los catálogos que han llegado hasta nosotros de bibliotecas de la época sabemos que en la actualidad sólo tenemos acceso a una quinta parte de cuanto escribió (27). De hecho, ninguno de los Diálogos aristotélicos ha sobrevivido y prácticamente todos los escritos aristotélicos que publicó en vida se han perdido. Él mismo denominó exotéricos

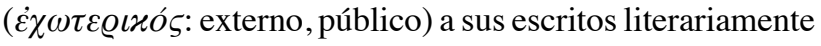
bien pulidos destinados a la publicación, para diferenciarlos

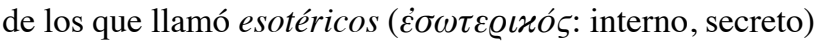
que correspondían a esbozos de obras aún por desarrollar en su aspecto literario, notas para dictar conferencias y clases, apuntes de discípulos avanzados que asistían a sus charlas y que, por tanto, sólo podrían explicarse bien en forma oral, razón por la cual también los llamó acroamáticos (de $\alpha \chi \varrho o \alpha \mu \alpha$ : lo que se escucha) (28). Quizás gracias al celo de sus discípulos por guardar las enseñanzas del maestro, sólo tenemos acceso hoy a los escritos aristotélicos de carácter esotérico o acroamático, vedados en tiempos de Aristóteles al público general. De ahí el aspecto rudo y fragmentario que siempre se le ha criticado a Aristóteles, que contrasta con los comentarios de quienes leyeron sus escritos exotéricos y dieron fe de un estilo literario excelso (Cicerón calificó la prosa de los Diálogos aristotélicos de "río de oro") (29) que lamentablemente no podemos disfrutar de manera directa.

Aunque parezca demasiado pretencioso intentar corregir ese vacío en el Aristóteles que ha llegado hasta nosotros, han sido muchos los intentos que se han hecho, desde perspectivas tanto aristotélicas como antiaristotélicas, de establecer una especie de canon con respecto a cómo debemos abordar la propia muerte y la de quienes nos rodean, incluyendo la de nuestros familiares, nuestros amigos y nuestros pacientes y, por qué no, la de todos nuestros congéneres (¿cabría también aquí, de la misma manera que al hablar de la vida buena y de la buena vida, establecer una diferenciación entre una muerte buena y una buena muerte?). El problema es que, como nos enseñó Aristóteles, carece de sentido hablar de una filosofía práctica que no se practica, sería en realidad teoría pura bajo un nombre travestido. Quizás habría que terminar por decir que de la misma manera que la vida buena (la eudaimonía) sólo puede ser vivida por cada uno de nosotros de acuerdo con nuestras potencialidades y a partir de nuestras propias decisiones, también nuestra propia muerte es un proceso que nos atañe individualmente y sobre el que tendríamos que tomar con mayor conciencia decisiones autónomas anticipadas.

Sin lugar a dudas no somos dioses y no podemos cambiar nuestro destino hacia la muerte inevitable (incluso aunque lo fuésemos, Herodoto nos recuerda que, según el oráculo de Delfos, "el destino ni los dioses lo pueden cambiar") (30), pero en ocasiones la vida nos da la oportunidad, como médicos o como pacientes, de modificar la forma en que nos llega la muerte. También esto tendría que contar, a pesar de Aristóteles pero sin llegar al extremo de Solón, en el nivel integral de eudaimonía. Lo que en la actualidad llamamos Calidad de Vida tiene que ver, indudablemente, con las características, cualidades y calidad, que revista nuestra muerte.

El término agonía en castellano se deriva, junto con sus equivalentes en otras lenguas romances e incluso anglo-

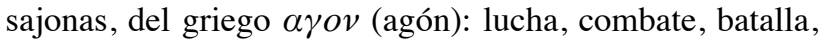
y se refiere al proceso final mediante el cual en muchos casos abandonamos la vida. La metáfora del combate era obvia desde los griegos clásicos, aunque en muchos casos no resulta claro si quien está próximo a morir lucha por aferrarse a la vida o por partir. El caso es que, desde antiguo, desde que tenemos acceso a medicamentos potentes para el alivio del dolor, existe la posibilidad de aliviar esa lucha. En la actualidad, gracias a los avances técnico científicos, las posibilidades terapéuticas que pueden emplearse con éxito en dicho alivio se han multiplicado. Un ejemplo claro de ello aparece en uno de los casos clínicos de la presente edición de Acta Médica Colombiana (31).

Se suele citar en el refranero médico un aforismo que se considera el epítome de la vocación del médico y de la enfermera con respecto al paciente: "Curar a veces, aliviar a menudo, consolar siempre". Por lo general se le cita en francés ("Guérir quelquefois, soulager souvent, consoler toujours"), quizás por la creencia (errónea) de que su autor fue Ambroise Paré. La máxima también ha sido atribuida (de manera igualmente errónea) a Hipócrates, a Florence Nightingale, a Louis Pasteur, a William Osler, a Edward Livingstone Trudeau y a Oliver Wendell Homes. Parece ser que la verdad es que no la dijo nadie o, por lo menos, nadie en particular, y que se trata de una de esas frases que se han ido gestando lentamente en el crisol del lenguaje vernáculo, evolucionando y cambiando mediante adiciones, sustracciones y modificaciones aquí y allá, hasta alcanzar su forma más perfecta (32).

En la actualidad, el proverbio en cuestión se cita siempre que se quiere hacer énfasis en el supuesto manto de olvido que los médicos hemos echado sobre la tercera parte de la frase: "consolar siempre". Ese olvido se atribuye, dependiendo de quien la cite, al abandono de los valores 
fundamentales de la práctica profesional del médico [los mismos que, sabiamente nos devela Álvaro Toro en la presente edición de Acta Médica Colombiana (33)], a las circunstancias socioeconómicas en las que nos a tocado ejercer la medicina en estos tiempos de la práctica médica gerenciada, a la despersonalización del trato entre los seres humanos en esta época de maquinización, automatización y realidad virtual. Yo creo que ese olvido no es cierto y que constituye más una excepción que una regla, pero que las excepciones, amplificadas de manera exagerada por la subcultura mediática, han dado lugar a una especie de mito urbano al respecto. Sea como fuere, quisiera hacer énfasis en que, incluso con lo maravilloso del consuelo, incluso con los efectos cuasi taumatúrgicos que pueden traer la palabra y el acompañamiento empático sobre el sufrimiento emocional de nuestros pacientes, resulta bien difícil consolar en medio del dolor físico. Por ello, debemos siempre disponer para nuestros pacientes, incluso o sobre todo si no es posible curarlos, el máximo de recursos tendientes al alivio del dolor. La Medicina Interna de nuestra época y en nuestro país, dispone del armamentarium suficiente para transformar el aforismo antedicho (incluso aunque Aristóteles se opusiera -cosa que no creo- por considerar de cobardes buscar alivio al dolor) en: "Curar a veces, aliviar siempre, consolar siempre".

\section{Referencias}

1. Herodoto. Los Nueve Libros de la Historia. 1, LXXXVI. Pou B (Traductor). Novena Edición. Madrid: Editorial EDAF; 2007: pp 52-55.

2. Ferrater-Mora J. Diccionario de Filosofía. Quinta Edición. Buenos Aires: Editorial Sudamericana; 1964: pp 539-540.

3. Dodds ER. Los Griegos y lo Irracional. Madrid: Alianza Editorial; 1997: p. 52.

4. Platón. Apología de Sócrates. 31d. Calonge-Ruiz J (Traductor). Barcelona: Editorial Gredos; 1993: pp 42-43.

5. Plato. The Republic (Cambridge Texts in the History of Political Thought). 1:352d. Ferrari GRF (Editor), Griffith T(Translator). First edition. Cambridge: Cambridge University Press; 2000: $\mathrm{p} 34$.

6. Platón. Apología de Sócrates. 21a. Calonge-Ruiz J (Traductor). Barcelona: Editorial Gredos; 1993: p 26.

7. Plato. Crito. 48b. In: Defence of Socrates, Euthyphro, Crito (Oxford World's Classics). Gallop D (Translator). Oxford: Oxford University Press; 1997: p 70.

8. Aristóteles. Ética a Nicómaco. 1095a. Araújo M, Marías J (Traductores). Octava Edición. Madrid: Centro de Estudios Políticos e Institucionales; 2002: pp 2-3.

9. Kraut R. Aristotle's Ethics. In Edward N. Zalta (editor) The Stanford Encyclopedia of Philosophy (Summer 2010 Edition), URL = <http://plato.stanford.edu/archives/ sum2010/entries/aristotle-ethics/>. Consultada el 20-02-2011.

10.Aristotle. Eudemian Ethics: Books I, II, and VIII (Clarendon Aristotle Series).
I.3, 1214b29-1215a3. Woods $M$ (Translator). Second Edition. Oxford: Oxford University Press; 1992: $p 3$.

11. Aristóteles. Ética a Nicómaco. 1097b. Araújo M, Marías J (Traductores). Octava Edición. Madrid: Centro de Estudios Políticos e Institucionales; 2002: pp 7-8.

12. Aristóteles. De Anima. 412 b 19. Traducción y notas de Tomás Calvo Martínez. Barcelona: Editorial Gredos; 1994.

13. Meyer M. The Mithras Liturgy. In A.J. Levine, Dale C. Allison, Jr., and John Dominic Crossan. The historical Jesus in context. New Jersey: Princeton University Press; 2006: pp 179-192.

14. Aristóteles. De Anima. 413 a 22. Traducción y notas de Tomás Calvo Martínez. Barcelona: Editorial Gredos; 1994.

15. Aristóteles. Ética a Nicómaco. 1144a. Araújo M, Marías J (Traductores). Octava Edición. Madrid: Centro de Estudios Políticos e Institucionales; 2002.

16. Aristóteles. Ética a Nicómaco. 1100a. Araújo M, Marías J (Traductores). Octava Edición. Madrid: Centro de Estudios Políticos e Institucionales; 2002: pp 12-13.

17. Aristóteles. Ética a Nicómaco. 1100a-1100b. Araújo M, Marías J (Traductores) Octava Edición. Madrid: Centro de Estudios Políticos e Institucionales; 2002: pp 13-14.

18. Haldane J. History: medieval and Renaissance Philosophy of Mind. In Guttenpplan S (Editor). A companion to the philosophy of mind. Oxford; Blackwell Publishers; 1994: 333-338.

19.Dod BG. Aristoteles latinus. In Kretzmann N, Kenny A, Pinborg J, Stump E (Editors). The Cambridge History of Later Medieval Philosophy: From the Rediscovery of Aristotle to the Disintegration of Scholasticism 1100-1600. Cambridge: Cambridge University Press; 1982: pp 45-79.

20. Blánquez-Frayle A. Diccionario Latino-Español. Barcelona: Editorial Ramón Sopena; 1961.

21. Real Academia Española. Diccionario de la Lengua Española. Vigésima segunda Edición. Madrid: Espasa-Calpe; 2001.

22. Real Academia Española. Diccionario de la Lengua Española. Avance de la Vigésima tercera Edición [Internet]. [Citado el 3 de marzo de 2011]. Disponible en: http://buscon.rae.es/draeI/

23. Nussbaum M. The Therapy of Desire: Theory and Practice in Hellenistic Ethics Princeton, NJ: Princeton UP; 1994: p 15.

24. Aristóteles. Ética a Nicómaco. 1103b. Araújo M, Marías J (Traductores). Octava Edición. Madrid: Centro de Estudios Políticos e Institucionales; 2002: p 20.

25. Aristóteles. Parva Naturalia. Serrano JA (Traductor). Primera Edición. Madrid: Alianza Editorial; 1993: pp 121-177.

26. Aristóteles. Ética a Nicómaco. 1116a. Araújo M, Marías J (Traductores). Octava Edición. Madrid: Centro de Estudios Políticos e Institucionales; 2002: p 44.

27. Barnes J. Aristóteles. Segunda Edición. Madrid: Ediciones Cátedra; 1993: p 14.

28. Jaeger W. Aristóteles. Gaós J (Traductor). Primera Edición. México: Fondo de Cultura Económica; 1997: pp 283-297.

29. Düring I. Aristóteles: exposición e interpretación de su pensamiento. Navarro B (Traductor). Segunda Edición. México: Universidad Nacional Autónoma de México; 1990: pp 74-75.

30. Herodoto. Los Nueve Libros de la Historia. 1, XCI. Pou B (Traductor). Novena Edición. Madrid: Editorial EDAF; 2007: pp 84-85.

31. Ramírez LJ, Santacruz JG, Arteaga C. Analgesia epidural en dolor crónico oncológico refractario. Acta Med Colomb 2011; 36: 35-36.

32. Payne IM. Guérir quelquefois, soulager souvent, consoler toujours. BMJ 1967; 4: 47-48.

33. Toro A. Consideraciones acerca de las cualidades del buen médico. Acta Med Colomb 2011; 36: 44-50. 